\title{
$I L-1 \beta$ Polymorphism and Expression Associated with Decreased Risk of Gastric Carcinoma: a Case Control Study in the Ethnic Kashmiri Population, India
}

\author{
Syed Irtiza ${ }^{1,2}$, Amat Us Samie ${ }^{3}$, Shakir Ali ${ }^{2}$, Mushtaq A Siddiqii ${ }^{4}$, Sameer H \\ Naqash $^{3}$, Aga Syed Sameer ${ }^{5 *}$
}

\begin{abstract}
The aim of this research was to investigate the possible association between gastric carcinoma (GC) and polymorphisms of the IL-1 $\beta$ gene in the Kashmiri population using peripheral blood DNA from 150 gastric carcinoma cases and 250 population controls with detailed data for clinicopathological characteristics of the

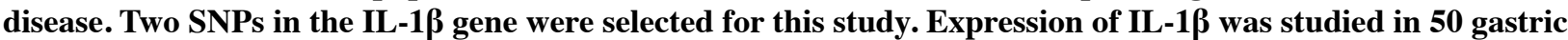
carcinoma cases using immunohistochemistry and RT-PCR and then correlated with genotype. The frequency of the IL-1ß-511 C allele was significantly higher in the GC case group $(53.3 \%)$ than in controls $(45.4 \%)$ with an odds ratio $(\mathrm{OR})$ of 0.73 and a $P$ value of 0.03 . Multivariate regression analysis showed associations of gastric

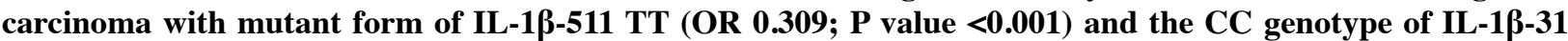

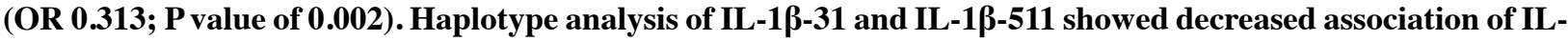

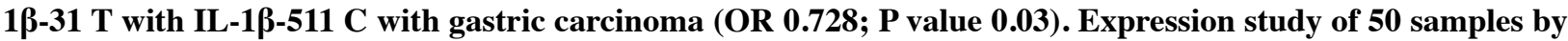
immunohistochemistry (IHC) and RT-PCR showed association with grade III and stage III+IV.After correlating the expression with polymorphism no association was found.
\end{abstract}

Keywords: Gastric carcinoma - interleukin polymorphisms - IHC - Kashmiri population - India

Asian Pac J Cancer Prev, 16 (5), 1987-1992

\section{Introduction}

Gastric carcinoma is the fourth most common cancer in the world and the second leading cause of cancer death. There are marked geographic variations in GC incidence, with the highest rates in Japan, China and South America and much lower rates in Western countries, including the USA (Parkin and Muir, 1988). A 2005 analysis of the worldwide incidence of, and mortality from, cancer showed that 934,000 cases of gastric carcinoma occurred in 2002 and that 700,000 patients die annually of this disease (Parkin et al., 2005).

The Kashmir valley (India) which borders the southern part of the high incidence belt represents a moderately high incidence area where incidence rates for gastric carcinoma were: men 36.70/100,000 per annum, women 9.9 (Khuroo et al., 1992). A number of recent studies have pointed to links between polymorphisms in interleukin genes and gastric cancer risk (Yang et al., 2013; Duan et al., 2014; Yu et al., 2014). The $I L-1 \beta$ gene encoding $I L-1 \beta$ has two diallelic polymorphisms in the promoter region at positions -511 and -31 , representing $\mathrm{C} / \mathrm{T}$ and $\mathrm{T} / \mathrm{C}$ transitions, respectively, in near total linkage disequilibrium (Machado et al., 2001, 2003; Hamajima et al., 2002). The less common alleles of these loci $(I L-1 \beta$ $511 \mathrm{~T}$ and $I L-1 \beta-31 \mathrm{C}$ ) have been found to be associated with gastric carcinoma (Bidwell et al., 1999; Machado et al., 2003; Xu et al., 2014). The capacity to produce different cytokines varies among different individuals and may be genetically determined.

Such interindividual differences can be attributed to several molecular mechanisms, including single nucleotide polymorphisms (SNPs) in the functional regions of cytokine or cytokine receptor genes. These SNPs may affect the overall expression and secretion of cytokines and may account for some of the heterogeneity of infectious diseases. These two SNPs were associated with an increased risk of gastric carcinoma in Scottish and Polish subjects (El-Omar et al., 2000) and were subsequently confirmed by studies in other ethnic groups from the USA (El-Omar et al., 2003) and Portugal (Machado et al., 2003). However, several other studies

${ }^{1}$ Department of Biochemistry, Faculty of Life Sciences, Jamia Hamdard University, New Delhi, ${ }^{2}$ Department of Microbiology, Medical College, ${ }^{3}$ Department of General surgery, Sher-I-Kashmir Institute of Medical Sciences, ${ }^{4}$ Taum Charitable Trust, Soura, ${ }^{5}$ Department of Biochemistry, Sher-I-Kashmir Institute of Medical Sciences Associated Medical College, Bemina, Srinagar, Kashmir, India*For correspondence: mousvi786@gmail.com 
failed to demonstrate the correlation (Kato et al., 2001; Zeng et al., 2003). The diverse ethnic background with different sample size, different environmental exposures infection in the population and genetic heterogeneity in the pathogenesis of gastric carcinoma may account for the variability in different studies. Therefore, whether these polymorphisms of $I L-1 \beta$ gene were related to the risk of gastric cancer remains inconclusive and needs to be replicated in ethnically diverse populations.

Here we describe a population-based case-control study of 150 incident gastric cancer cases and 250 cancer free controls frequency-matched to the cases by age and sex from Kashmir (India), an area of high risk of gastric carcinoma, to test the hypothesis that these two promoter variants of $I L-1 \beta$ and its expression contribute to host susceptibility to gastric cancer.

\section{Materials and Methods}

\section{Study population}

All blood and tissue with adjacent normal samples for this study were taken from 150 gastric carcinoma patients registered in the Department of Surgical Gastroenterology, Sher-I-Kashmir Institute of Medical Sciences, from March 2009 to March 2012. Tumor types and stages were determined by two experienced pathologists. Blood samples of 250 age, gender, dwelling and smoking matched cases with no signs of any malignancy or any other disease were collected for controls (Table 1). Data on all gastric carcinoma patients were obtained from personal interviews with patients and or guardians, medical records and pathology reports. The data collected included gender, age, dwelling, tumor location, lymph node status, site of growth and EGD biopsy.

All patients and or guardians were informed about the study, and their consent to participate was obtained on a predesigned questionnaire (available on request). The collection and use of tumor and blood samples for this study was approved by the appropriate Institutional Ethics Committee.

DNA extraction, Polymerase chain reaction-restriction fragment length polymorphism and Sequencing

Genomic DNA samples were obtained from blood lymphocytes using a genomic DNA extraction kit (Bioserve Biotechnologies Pvt. Ltd., India) or by phenol/ chloroform method. Previously reported primers for $I L$ $1 \beta$-31 Forward 5'-AGAAGCTTCCACCAATACTC-3' Reverse 5-AGCACCTAGTTGTAAGGAAG-3' and for $I L-1 \beta-511$ forward 5-GGCATTGATCTGGTTCATC-3 and reverse 5-GTTTAGGAATCTTCCCACTT-3 were used for the am $\neg$ plification of the target regions of the $I L$ $1 \beta$ polymorphisms. PCR was carried out in a final volume of $25 \mu \mathrm{L}$ containing $50 \mathrm{ng}$ genomic DNA template, $1 \mathrm{X}$ PCR buffer (Biotools) with $2 \mathrm{mM} \mathrm{MgCl}_{2}, 0.4 \mu \mathrm{M}$ of each primer (Sigma), $50 \mu \mathrm{M}$ dNTPs (Biotools), and 0.5 U DNA polymerase (invitrogen). For PCR amplification annealing at $57^{\circ} \mathrm{C}$ for $I L-1 \beta-31$ and $57^{\circ} \mathrm{C}$ for $I L-1 \beta-511$ were used. For RFLP, the PCR products of $I L-1 \beta-31$ and $I L-1 \beta-511$ SNPs were digested with AluI and AvaI $\left(1 \mathrm{U}\right.$ at $37^{\circ} \mathrm{C}$ for $16 \mathrm{~h}$ ) (Fermentas). In the case of $I L-1 \beta-31$ polymorphism, the TT wild produced two bands (137 and $102 \mathrm{bp}$ ); the CC variant was identified by a single band (239 bp), and heterozygous TC variant displayed three bands $(239,137$, and $102 \mathrm{bp}$ ), In the case of $I L-1 \beta-511$ polymorphism, the CC wild produced two bands (119 and $114 \mathrm{bp}$ ); the TT variant was identified by a single band (304 bp), and heterozygous TC variant displayed three bands (304, 190 , and 114 bp). DNA fragments were electrophoresed through a $3 \%$ agarose gel for resolution.

The genotypes of $>20 \%$ of the samples were double blindly reassessed to confirm the results by two independent researchers. Also the Purified PCR products showing digestion by RFLP analysis as well as randomly chosen samples were used for direct DNA sequencing using the ABI prism 310 automated DNA sequencer. To minimize the sequencing artifacts by PCR, products from at least two different PCRs were sequenced using both forward and reverse primers.

\section{Immunohistochemistry}

Immunostaining was done by the method of Ahmad et al (2011). Sections of formalin-fixed, paraffin-embedded gastric Tissue (Tumor and Adjacent Normal) were obtained on poly-l-lysine coated slides. Sections were deparaffinized in xylene, then rehydrated through a graded alcohol series. Antigen retrieval was performed by incubating slides in citrate buffer $(\mathrm{pH} 6.0)(10 \mathrm{mM})$ at $95^{\circ} \mathrm{C}$ for $20 \mathrm{~min}$. Endogenous peroxidase activity was blocked with $3 \% \mathrm{H}_{2} \mathrm{O}_{2}$ for $30 \mathrm{~min}$. To $I L-1 \beta$ immunoreactivities, sections were incubated under humid conditions overnight at $4^{\circ} \mathrm{C}$ with the following monoclonal antibodies: anti $I L$ $1 \beta$ antibody (1:400; Thermo Fisher Scientific, USA). Next day, the slides were washed three times in Tris buffers (pH 6.0) and were incubated with a biotinylated Human Anti-Polyvalent Plus (Thermo Fisher Scientific, USA) for $30 \mathrm{~min}$ at room temperature.

This step was followed by further wash in Tris buffer and incubation of slides at room temperature with a Streptavidin Peroxidase Plus (Thermo Fisher Scientific, USA) that binds to the biotin present on the secondary antibody. After washing in Tris buffer, the immunostaining reaction product was developed using 3, 3-diaminobenzidine (DAB Plus substrate, Thermo Fisher Scientific, USA). After immunoreactivity, slides were dipped in distilled water, counterstained with Harris hematoxylin and finally the sections were dehydrated in xylene, mounted with DPX and cover slipped. Negative controls included staining tissue sections with omission of the primary antibody whereas positive control slides were also run in parallel in each case. Slides prepared for each case were examined by light microscopy.

\section{Quantitative evaluation of $I L-1 B$}

According to the diffuseness of the DAB staining, sections were graded as 0 (no staining), 1 (staining, 25\%), 2 (staining between $25 \%$ and $50 \%$ ), 3 (staining between $50 \%$ and $75 \%$ ), or 4 (staining $>75 \%$ ). According to staining intensity, sections were graded as follows: 0 (no staining), 1 (weak but detectable staining), 2 (distinct staining) or 3 (intense staining). Immunohistochemical staining scores were obtained by adding the diffuseness and intensity 
IL-1 $\beta$ Polymorphisms and Risk of Gastric Carcinoma: a Case Control Study in an Ethnic Kashmiri Population scores. All slides were examined by two independent observers who were unaware of the experimental protocol. The slides with discrepant evaluations were reevaluated, and a consensus was reached. Measurements were carried out using an Olympus BX51 (Hamburg, Germany) microscope using objectives with $10 \times$ and $40 \times$ magnifications.

Semiquantitative Reverse Transcription-PCR (RT-PCR)

Total RNA was eextracted after homogenisation with $1 \mathrm{ml} / 100 \mathrm{mg}$ of gastric tissues by TRIzol (Invitrogen Life Technologies, USA). RNA extracted's quantity and quality was analyzed by UV spectrophotometer and agarose gel electrophoresis. One microgram total RNA was reverse transcribed using RevertAidTM First Strand cDNA Synthesis Kit (Fermentas Life Sciences, USA). By use of first-strand cDNA as a template, the specific primers for $I L-1 \beta$ Forward 5-CAGTGAAATGATGGCTTATTA-C-3 and Reverse 5-CTTTCAACACGCAGGACAGGT-3 primers yield a 548-bp product and $G A P D H$ Forward 5-CAAGGTCATCCATGACAACTTTG-3 and Reverse 5-GTCCACCACCCTGTTGCTGTAG-3 primers yield 496 bp (as reference gene) were subjected to 35 cycles of PCR amplification $\left(30 \mathrm{~s}\right.$ denaturation at $94^{\circ} \mathrm{C}, 30 \mathrm{~s}$ annealing temperature $\left(I L-1 \beta 55^{\circ} \mathrm{C}\right.$ and $G A P D H 58^{\circ} \mathrm{C}, 2$ min extension at $72^{\circ} \mathrm{C}$ ) in a thermal cycler.

The amplified products were resolved by gel electrophoresis on $1.5 \%$ agarose and visualized by ethidium bromide $(0.5 \mu \mathrm{g} / \mathrm{ml})$. Images of the RT-PCR ethidium bromide stained agarose gel were acquired using AlphaImager TM Gel Documentation, USA. Quantification of the results was accomplished by measuring the optical density of the cDNA bands. The intensities of bands of above mentioned genes were normalized relative to that of $G A P D H$ bands by dividing the former by the GAPDH specific PCR product densities. $G A P D H$ acted as control for sample to sample variations in reverse transcription and PCR conditions and to control for the extent of degradation and recovery of RNA.

\section{Statistical analysis}

Statistical analyses were performed with the SPSS version 16 software. Observed frequencies of genotypes in gastric carcinoma patients were compared to controls using chi-square or Fisher exact tests when expected frequencies were small. The chi-square test was used to verify whether genotype distributions were in Hardy-
Weinberg equilibrium. Statistical significance was set at $\mathrm{p}<0.05$. Odds ratio at $95 \%$ confidence intervals $(95 \% \mathrm{CI})$ and $\mathrm{P}$ values were computed by binary logistic regression, and all results were adjusted for age, gender, smoking and dwelling.

The independent sample Student's t-test was applied to check association between cases and controls. The $\mathrm{P}$ values $<0.05$ were considered to indicate statistical significance in these tests. All analyses were performed using the statistical package SPSS ver. 16 (SPSS Inc., Chicago, IL). Haplotype analysis was performed by Shesis online version.

\section{Results}

A total of 150 gastric carcinoma patients and 250 control subjects were included in this study. The patients comprised 112 males and 38 females $(\mathrm{M} / \mathrm{F}$ ratio=2.95), and the control subjects con $\neg$ sisted of 162 males and 88 females $(\mathrm{M} / \mathrm{F}$ ratio=1.84). There were 90 rural and 60 urban cases. There were 98 smokers and 52 non-smokers Table 1. In this study, we found that the genotype frequencies in cases and controls were in Hardy-Weinberg equilibrium. The genotypic distribution and allelic frequencies of $I L$ $1 \beta$ gene polymorphism in patients and controls are given in Table 2 . The frequency of $I L-1 \beta-511 \mathrm{C}$ allele was significantly higher in GC cases group (53.3\%) than that in controls (45.4\%) with odds ratio 0.73 and $\mathrm{P}$ value 0.03 .

The correlation of $I L-1 \beta$ polymorphic status with the clinicopathological characteristics was carefully analyzed. It was found that the $I L-1 \beta-31$ was associated with clinical stage, grade and sex with gastric carcinoma also $I L-1 \beta-511$ was associated with clinical tumor stage Table 2, but after analyzing by multivariate regression analysis (Table 3 ) association of mutant form of $I L-1 \beta-511 \mathrm{TT}$ with gastric carcinoma with odds ratio of 0.039 and $\mathrm{P}$ value of $<0.001$ and association of CC genotype of $I L-1 \beta-31$ with odds ratio of 0.313 and $\mathrm{P}$ value of 0.002 was found. Further statistics for haplotype analysis (Table 4 ) of $I L-1 \beta-31$ and $I L-1 \beta-511$ shows association of $I L-1 \beta-31 \mathrm{~T}$ with $I L-1 \beta-511 \mathrm{C}$ with odds ratio of 0.728 and $\mathrm{P}$ value of 0.03 with gastric carcinoma.

Expression study of 50 samples by immunohistochemistry and RT PCR showed association with grade III and stage III+IV (Table 5 and 6). No correlation between expression and polymorphisms was found.

\section{Table 1. Clinical Characteristic of Gastric Carcinoma Patients and Controls}

\begin{tabular}{|c|c|c|c|c|}
\hline \multicolumn{2}{|l|}{ Variables } & \multirow{2}{*}{$\begin{array}{c}\text { Cases } \\
\mathrm{N}=150(\%)\end{array}$} & \multirow{2}{*}{$\begin{array}{c}\text { Controls } \\
\mathrm{N}=250(\%)\end{array}$} & \multirow{2}{*}{$\begin{array}{c}\mathrm{P} \text { Value } \\
\mathrm{p}>0.05\end{array}$} \\
\hline Age & $\begin{array}{l}<45 \\
>45\end{array}$ & & & \\
\hline $\operatorname{Sex}$ & $\begin{array}{l}\text { Male } \\
\text { Female }\end{array}$ & $\begin{array}{r}112(73.3) \\
38(26.5)\end{array}$ & $\begin{array}{r}162(64.8) \\
88(35.2)\end{array}$ & $\mathrm{p}>0.05$ \\
\hline Dwelling & $\begin{array}{l}\text { Rural } \\
\text { Urban }\end{array}$ & $\begin{array}{l}90(60.0) \\
60(40.0)\end{array}$ & $\begin{array}{r}170(68.0) \\
80(32.0)\end{array}$ & $\mathrm{p}>0.05$ \\
\hline Hot Salt tea consumption & $\begin{array}{l}<4 \text { cups/day } \\
>4 \text { cups /day }\end{array}$ & $\begin{array}{l}94(62.7) \\
56(37.3)\end{array}$ & $\begin{array}{r}190(76.0) \\
60(24.0)\end{array}$ & $\mathrm{p}<0.01$ \\
\hline Smoking & $\begin{array}{l}\text { Ever } \\
\text { Never }\end{array}$ & $\begin{array}{l}98(65.3) \\
52(34.7)\end{array}$ & $\begin{array}{l}130(52.0) \\
120(48.0)\end{array}$ & $\mathrm{P}<0.05$ \\
\hline
\end{tabular}


Syed Irtiza et al

Table 2. Association between IL-1 B Genotypes and Clinicopathologic Characteristics

\begin{tabular}{|c|c|c|c|c|c|c|c|c|c|c|c|}
\hline \multicolumn{2}{|c|}{ Clinical Parameters } & \multicolumn{4}{|c|}{ IL 1B 31 genotype } & \multirow[t]{2}{*}{$P$ value } & \multicolumn{4}{|c|}{ IL 1B 511genotype } & \multirow[t]{2}{*}{$P$ value } \\
\hline & & TT & CT & $\mathrm{CC}$ & Total & & $\overline{C C}$ & CT & TT & Total & \\
\hline \multirow[t]{2}{*}{ Age } & $<45$ & 42 & 51 & 17 & 110 & \multirow[t]{2}{*}{0.396} & 38 & 42 & 30 & 110 & \multirow[t]{2}{*}{0.75} \\
\hline & $>45$ & 15 & 22 & 3 & 40 & & 12 & 18 & 10 & 40 & \\
\hline \multirow[t]{2}{*}{ Sex } & Male & 41 & 60 & 11 & 112 & \multirow[t]{2}{*}{0.04} & 33 & 44 & 35 & 112 & \multirow[t]{2}{*}{0.06} \\
\hline & Female & 16 & 13 & 9 & 38 & & 17 & 16 & 5 & 38 & \\
\hline \multirow[t]{2}{*}{ Dwelling } & Rural & 34 & 43 & 13 & 90 & \multirow[t]{2}{*}{0.88} & 24 & 39 & 27 & 90 & \multirow[t]{2}{*}{0.102} \\
\hline & Urban & 23 & 30 & 7 & 60 & & 26 & 21 & 13 & 60 & \\
\hline \multirow[t]{2}{*}{ Smoking } & Ever & 28 & 55 & 15 & 98 & \multirow[t]{2}{*}{0.005} & 32 & 39 & 27 & 98 & \multirow[t]{2}{*}{0.94} \\
\hline & Never & 29 & 18 & 5 & 52 & & 18 & 21 & 13 & 52 & \\
\hline \multicolumn{12}{|c|}{ Hot Salt tea consumption } \\
\hline & $<4$ cups/day & 37 & 47 & 10 & 94 & \multirow[t]{2}{*}{0.45} & 37 & 36 & 21 & 94 & \multirow[t]{2}{*}{0.095} \\
\hline & $>4$ cups /day & 20 & 26 & 10 & 56 & & 13 & 24 & 19 & 56 & \\
\hline \multirow{2}{*}{$\begin{array}{l}\text { Site of } \\
\text { growth }\end{array}$} & GE junction & 48 & 60 & 16 & 120 & \multirow[t]{2}{*}{0.9} & 36 & 52 & 32 & 120 & \multirow[t]{2}{*}{0.16} \\
\hline & Others & 9 & 13 & 4 & 30 & & 14 & 8 & 8 & 30 & \\
\hline \multicolumn{12}{|c|}{ EGD biopsy } \\
\hline & Intestinal & 34 & 55 & 13 & 102 & \multirow[t]{2}{*}{0.155} & 37 & 35 & 30 & 102 & \multirow[t]{2}{*}{0.12} \\
\hline & Diffuse & 23 & 18 & 7 & 48 & & 13 & 25 & 10 & 48 & \\
\hline \multicolumn{12}{|c|}{ Lymph node involvement } \\
\hline & Yes & 30 & 32 & 18 & 80 & \multirow[t]{2}{*}{0.001} & 24 & 38 & 18 & 80 & \multirow[t]{2}{*}{0.128} \\
\hline & No & 27 & 41 & 2 & 70 & & 26 & 22 & 22 & 70 & \\
\hline \multicolumn{12}{|c|}{ Clinical tumor stage } \\
\hline & I & 31 & 32 & 4 & 67 & & 11 & 31 & 25 & 67 & \\
\hline & II & 11 & 18 & 11 & 40 & 0.02 & 18 & 15 & 7 & 40 & 0.0002 \\
\hline & III & 15 & 23 & 5 & 43 & & 21 & 14 & 8 & 43 & \\
\hline Grade & I & 41 & 67 & 15 & 123 & 0.009 & 37 & 54 & 32 & 123 & 0.087 \\
\hline & II+III & 16 & 6 & 5 & 27 & & 13 & 6 & 8 & 27 & \\
\hline
\end{tabular}

Table 3. Multivariate Logistic Regression Model for Association of IL 1 B Polymorphism with Gastric Carcinoma Risk

\begin{tabular}{|c|c|c|c|c|c|c|c|c|}
\hline Genotype & Cases $(\%)$ & Control (\%) & OR & CI $(95 \%)$ & $\mathrm{P}$ value & OR & CI $(95 \%)$ & $P$ value \\
\hline \multicolumn{9}{|l|}{ IL-1B-31 } \\
\hline $\mathrm{TT}$ & $57(38.0 \%)$ & $84(33.6 \%)$ & 1.0 (Ref) & & & & & \\
\hline $\mathrm{CT}$ & $73(48.6 \%)$ & $111(44.4 \%)$ & 0.969 & $(0.620-1.515)$ & 0.91 & & & \\
\hline $\mathrm{CC}$ & $20(13.3 \%)$ & $55(22.0 \%)$ & 0.536 & $(0.292-0.985)$ & 0.05 & 0.313 & $0.150-0.654$ & 0.002 \\
\hline $\mathrm{C}$ & $187(62.3 \%)$ & $279(55.8 \%)$ & 1.0 (Ref) & & & & & \\
\hline $\mathrm{T}$ & $113(37.7 \%)$ & $221(44.2 \%)$ & 1.31 & $(0.97-1.76)$ & 0.07 & & & \\
\hline \multicolumn{9}{|l|}{ IL-1B-511 } \\
\hline $\mathrm{CC}$ & $50(33.3 \%)$ & $66(26.4 \%)$ & 1.0 (Ref) & & & & & \\
\hline $\mathrm{CT}$ & $60(40.0 \%)$ & $95(38.0 \%)$ & 0.834 & $(0.512-1.358)$ & 0.53 & & & \\
\hline $\mathrm{TT}$ & $40(26.7 \%)$ & $89(35.6 \%)$ & 0.593 & $(0.35-1.00)$ & 0.06 & 0.309 & $0.167-0.571$ & 0.000 \\
\hline $\mathrm{T}$ & $140(46.7 \%)$ & $273(54.6 \%)$ & 1.0 (Ref) & & & & & \\
\hline $\mathrm{C}$ & $160(53.3 \%)$ & $227(45.4 \%)$ & 0.73 & $(0.55-0.97)$ & 0.03 & & & \\
\hline
\end{tabular}

Table 4. Haplotype Analysis of IL 1B in Gastric Carcinomas

\begin{tabular}{|c|c|c|c|c|c|c|c|}
\hline Haplotype & & Control & Cases & chi square & P value & OR & $\mathrm{CI}(95 \%)$ \\
\hline IL 1B 31 & IL 1B 511 & & & & & & \\
\hline $\mathrm{T}$ & $\mathrm{C}$ & $227(45.4)$ & $160(55.3)$ & 4.725 & 0.03 & 0.728 & $0.546-0.970$ \\
\hline $\mathrm{T}$ & $\mathrm{T}$ & $52(10.4)$ & $27(9.0)$ & 0.413 & 0.52 & 1.714 & $0.720-1.913$ \\
\hline $\mathrm{C}$ & $\mathrm{T}$ & $221(44.2)$ & $113(37.7)$ & 3.291 & 0.07 & 1.311 & $0.978-1.757$ \\
\hline
\end{tabular}

Table 5. Immunohistochemical Scores of IL 1B Expression in Gastric Carcinomas

\begin{tabular}{|c|c|c|c|c|c|c|}
\hline \multirow{2}{*}{\multicolumn{2}{|c|}{ Parameters }} & \multicolumn{4}{|c|}{ Immunohistochemical score of IL 1 B expression $(\mathrm{N}=50)$} & \multirow[t]{2}{*}{$P$ Value } \\
\hline & & 0 & 1 & 2 & 3 & \\
\hline \multirow[t]{3}{*}{ Grade } & I & 2 & 18 & 6 & 0 & Ref 1 \\
\hline & II & 0 & 8 & 2 & 1 & 0.494 \\
\hline & III & 3 & 3 & 4 & 3 & 0.007 \\
\hline \multirow[t]{3}{*}{ Stage } & I & 0 & 30 & 2 & 0 & Ref 1 \\
\hline & II & 1 & 6 & 2 & 0 & 0.06 \\
\hline & III+IV & 1 & 1 & 6 & 1 & $<0.001$ \\
\hline
\end{tabular}

0 is absent staining, 1 is weak staining, 2 is moderate staining and 3 is strong staining. 
IL-1 $\beta$ Polymorphisms and Risk of Gastric Carcinoma: a Case Control Study in an Ethnic Kashmiri Population

Table 6. Relationship of IL-1B Polymorphisms and IL-1B Expression in Gastric Cancer

\begin{tabular}{|c|c|c|c|c|}
\hline Genotypes & \multicolumn{4}{|c|}{$\begin{array}{l}\text { Number Underexpression Overexpression P Value } \\
\qquad(0+1)\end{array}$} \\
\hline \multicolumn{5}{|l|}{ IL-1B-31 } \\
\hline TT & 17 & 12 & 5 & Ref 1 \\
\hline CT & 23 & 16 & 7 & 1 \\
\hline $\mathrm{TC}$ & 10 & 6 & 4 & 0.44 \\
\hline $\mathrm{TC}+\mathrm{CT}$ & 33 & 22 & 11 & 0.77 \\
\hline \multicolumn{5}{|l|}{ IL-1B-511 } \\
\hline $\mathrm{CC}$ & 18 & 11 & 7 & Ref 1 \\
\hline $\mathrm{CT}$ & 19 & 13 & 6 & 0.64 \\
\hline $\mathrm{TC}$ & 13 & 10 & 3 & 0.29 \\
\hline $\mathrm{TC}+\mathrm{CT}$ & 32 & 23 & 9 & 0.43 \\
\hline
\end{tabular}

\section{Discussion}

In this population-based case-control study, we found significantly decreased risk of gastric carcinoma associated with both the $I L-1 \beta-31 \mathrm{~T}$ and $-511 \mathrm{C}$ variant genotypes and the risk was significantly more evident among individuals with increased expression of $I L-1 \beta$, suggesting that the promoter variants of $I L-1 \beta$ may play an important role in decreasing gastric carcinogenesis in Kashmiri population and may modulate the risk of gastric carcinoma.

Our study found that the $-31 \mathrm{~T}$ allele is associated with an decreased risk of gastric carcinoma in this Kashmiri population, which is consistent with the meta analysis done by Kamangar et al (2006), but not with El-Omar et al. (2000) in the Scottish and Polish population and Yang et al. (2004) in Chinese population. The genotype frequencies of the $-31 \mathrm{~T}$ polymorphism in our study was significantly different with those in the study of Yang et al. (2004) both in cases and controls, but was consistent with those in Asian populations (Kikuchi et al., 2002; Chang et al., 2002; Zeng et al., 2003).The genotype frequencies of $I L-1 \beta-511$ are CC (33.3\%), CT (40.0\%), and TT (26.7\%), compared with Japanese populations have almost same frequency of the $\mathrm{T}$ allele and of the $\mathrm{C}$ allele and lower than American Caucasian, Wet Scotland and higher frequency of the alleles than Taiwan Chinese and Koreans (Pyo et al., 2003). On the one hand, polymorphisms in $I L-1 \beta$ may reduce gastric carcinoma risk by mounting a stronger inflammatory reaction reducing gastric injury in response to a wide variety of noxious stimuli, and increasing apoptosis of gastric epithelial cells. On the other hand, stronger inflammatory reaction may increase cancer risk by causing genomic damage to gastric cells, mucosal atrophy, and secondary hypochlorhydria and bacterial overgrowth.

Gastric carcinoma, like many malignancies, is a result of interaction between genetic factors of the host together with dietary and other factors in the environment. Epidemiological studies on Northern Chinese and American Japanese in Hawaii lent strong support to the effects of lack of fresh fruit and vegetable, smoking, and consumption of salty food in the development of gastric cancer (You et al., 1988; Nomura et al., 1990).

According to a recent report, the effect of the $I L-1 \beta-511$ TT genotype on gastric carcinogenesis is ambiguous in areas with a high prevalence of gastric carcinoma (Malaty et al., 1997). In our study it was found that $I L-1 \beta-511$ TT is highly associated with decreased risk of gastric carcinoma. It appears that there are population-specific differences in the risk genotypes of $I L-1 \beta-511$ and -31 loci with respect to gastric carcinoma predisposition.

In the population of southern Mexico, $-511 \mathrm{C}$ or $-31 \mathrm{~T}$ alleles and $-511 \mathrm{C} /-31 \mathrm{~T}$ or $-511 \mathrm{~T} /-31 \mathrm{~T}$ haplotypes of $I L$ $1 \beta$ increase the risk of chronic gastritis and gastric ulcer (Martinez-Carrillo et al., 2010). In our study it was found that $-511 \mathrm{C} /-31 \mathrm{~T}$ or $-511 \mathrm{~T} /-31 \mathrm{C}$ haplotypes are associated with decreased risk of gastric carcinoma. The results of this study support the hypothesis that the combined effect of genetic factors and environmental factors of the host, such as $I L-1 \beta-511 \mathrm{C} / \mathrm{IL}-1 \mathrm{~B}-31 \mathrm{~T}$ polymorphisms and smoking can play an important role in development of chronic gastritis and gastric carcinoma in the Kashmiri population. Greater risk of chronic gastritis and gastric carcinoma has also been reported in Japanese population with the -511CC genotype and in Chinese population with the CT genotype (Matsukura et al., 2003) which is consistent with our study.

The biallelic polymorphisms in positions -31 and -511 of $I L-1 \beta$ influence cytokine expression; allele $\mathrm{T}$ in position -31 forms a TATA-Box that can potentiate and induce expression of $I L-1 \beta$ (El-Omar et al., 2003; Chang et al., 2005). In this study, we have identified the relationships between inflammatory cytokines in gastric carcinoma along different stages of disease, our study indicate that the expression of the inflammatory cytokine $I L-1 \beta$ is coordinated in crucial stages along the process of disease progression. Here we find that these two promoter variants of $I L-1 \beta$ and its expression contribute to host susceptibility to gastric carcinoma.

These findings suggest that $I L-1 \beta$ is associated with decreased risk of gastric carcinoma in Kashmiri population.

\section{Acknowledgements}

The authors wish to thank everyone who helped in this study

\section{References}

Ahmad ST, Seth A, Nafees S, et al (2011). Preclinical renal cancer chemopreventive efficacy of geraniol by modulation of multiple molecular pathways. Toxicology, 290, 69-81.

Bidwell J1, Keen L, Gallagher G, Kimberly R, Huizinga T, et al (1999). Cytokine gene polymorphism in human disease: on-line databases. Genes Immun, 1, 3-19.

Chang YT, Wu MS, Shun CT, Lin MT, Chang MC, Lin JT (2002). Association of polymorphisms of interleukin-1 beta gene and Helicobacter pylori infection with the risk of gastric ulcer. Hepatogastroenterol, 49, 1474-6.

Chang YW, Jang JY, Kim NH, Lee JW, Lee HJ, Jung WW, (2005). Interleukin-1B (IL-1B) polymorphisms and gastric mucosal levels of IL- $1 \beta$ cytokine in Korean patients with gastric cancer. Int J Cancer, 114, 465-71.

Duan Y, Shi JN, Pan C, Chen HL, Zhang SZ (2014). Association between the interleukin-17A -197G >A (rs2275913) polymorphism and risk of digestive cancer. Asian Pac J 


\section{Syed Irtiza et al}

Cancer Prev, 15, 9295-300.

El-Omar EM, Carrington M, Chow WH, et al (2000). Interleukin-1 polymorphisms associated with increased risk of gastric cancer. Nature, 404, 398-402

El-Omar EM, Gammon MD, Vaughan TL, et al (2003). Increased risk of non-cardia gastric cancer associated with proinflammatory cytokine gene polymorphisms. Gastroenterol, 124, 1193-201.

Hamajima N, Ito H, Matsuo K, Tajima K, Tominaga S (2002). Helicobacter pylori seropositivity, the interleukin 1B polymorphism and smoking among first-visit outpatients. Asian Pac J Cancer Prev, 3, 23-28.

Kamangar F, Cheng C, Abnet CC, Rabkin CS (2006). Interleukin$1 \mathrm{~B}$ polymorphisms and gastric cancer risk-a meta-analysis. Cancer Epidemiol Biomarkers Prev, 15, 1920-8.

Kato S, Onda M, Yamada S, Matsuda N, Tokunaga A, Matsukura $\mathrm{N}$ (2001). Association of the interleukin-1 beta genetic polymorphism and gastric cancer risk in Japanese. $J$ Gastroenterol, 36, 696-9.

Khuroo MS, Mahajan R, Banday MA (1992). High incidence of oesophageal and gastric cancer in Kashmir in a population with special personal and dietary habits. Gut, 33, 11-15.

Kikuchi M, Hishida A, Ishikawa K, et al (2002). Associations between serum $\mathrm{C}$ reactive protein (CRP) levels in interleukin $1 \mathrm{~B}$, and tumor necrosis factor genes among Japanese health checkup examinees. Asian Pac J Cancer Prev, 3, 23-8.

Machado JC, Canedo P, Pharoah P, et al (2003). A proinflammatory genetic profile increases the risk for chronic atrophic gastritis and gastric carcinoma. Gastroenterology, 125, 364-371.

Machado JC, Sousa S, Carvalho R, et al (2001). Interleukin 1B and interleukin 1RN polymorphisms are associated with increased risk of gastric carcinoma. Gastroenterology, 121, 823-829.

Malaty HM, Kim JG, El-Zimaity HM, Graham DY (1997). High prevalence of duodenal ulcer and gastric cancer in dyspeptic patients in Korea. Scand. J Gastroenterol, 32, 751-4.

Martinez-Carrillo DN, Garza-Gonzalez E, Betancourt-Linares $\mathrm{R}$, et al (2010). Association of IL1B -511C/-31T haplotype and Helicobacter pylori vacA genotypes with gastric ulcer and chronic gastritis. BMC Gastroenterol, 10, 126.

Matsukura N, Yamada S, Kato S, et al (2003). Genetic differences in interleukin-1 beta polymorphisms among four Asian populations: An analysis of the Asian paradox between $H$. pylori infection and gastric cancer incidence. J Exp Clin Cancer Res, 22, 47-55.

Nomura A, Grove JS, Stemmermann GN, Severson RK (1990). A prospective study of stomach cancer and its relation to diet, cigarettes, and alcohol consumption. Cancer Res, 50, 627-31.

Parkin DM, Ferlay J, Pisani P (2005). Global cancer statistics, 2002. CA Cancer J Clin, 55, 74-108.

Parkin DM, Muir CS (1988). Estimates of the worldwide frequency of sixteen major cancers in 1980. Int J Cancer, 41, 184-197.

Pyo C-W, Kim YK, Choi H-B, et al (2003). Polymorphisms of IL-1B, IL-1RN, IL-2, IL-4, IL-6, IL-10, and IFN- genes in the Korean population. Human Immunology, 64, 979-89.

Xu H, Ding Q, Jiang HW (2014). Genetic polymorphism of interleukin-1A (IL-1A), IL-1B and IL-1 receptor antagonist (IL-1RN) and prostate cancer risk. Asian Pac J Cancer Prev, 15, 8741-7.

Yang J, Hu Z, Xu Y, Shen J, Niu J, Hu X, et al (2004). Interleukin$1 \mathrm{~B}$ gene promoter variants are associated with an increased risk of gastric cancer in a Chinese population. Cancer Letters, 215, 191-8.

Yang L, Sun MJ, Liu JW, Xu Q, Yuan Y (2013). IL-6-6331 (T/C, rs10499563) is associated with decreased risk of gastric cancer in Northern Chinese. Asian Pac J Cancer Prev, 14,
7467-72.

You WC, Blot WJ, Chang YS, et al (1988). Diet and high risk of stomach cancer in Shandong, China. Cancer Res, 48, 3518-23.

Yu H, Sun S, Liu F, Xu QH (2014). Meta-analysis of associations between interleukin-17 gene polymorphisms and risk of gastric cancer. Asian Pac J Cancer Prev, 15, 8709-13.

Zeng ZR, Hu PJ, Hu S, Pang RP, Chen MH, Ng M, et al (2003). Association of interleukin 1B gene polymorphism and gastric cancers in high and low prevalence regions in China. Gut, 52, 1684-9. 